\title{
Oral Contraceptives after Liver Disease
}

\author{
A. EISALO, A. KONTTINEN, O. HIETALA
}

British Medical fournal, 1971, 3, 561-562

\section{Summary}

Administration of oral contraceptives to 10 women was started two weeks after the normalization of the serum enzyme activities in the convalescent period of viral hepatitis, and to five women eight weeks after an operation of obstructive jaundice. Routine liver function tests were performed at intervals of two weeks for two to three months. The liver function tests stayed within normal limits during the follow-up period.

\section{Introduction}

It is usually said that in a hepatic illness it is safe to resume oral contraception after the acute phase of the disease is over. To try to establish a more precise, workable ruling we took 14 days after the bilirubin and serum aminotransferase tests had returned to normal as the starting point for resuming oral contraceptives in a small group of women recovering from virus hepatitis. In another, smaller group of women who had had an operation for obstructive jaundice we started oral contraceptives eight weeks after the operation. In each group we observed the effect of the oral contraceptives on the liver function tests at fortnightly intervals, and the results are reported.

\section{Patients and Methods}

There were two groups of patients, one of 10 women aged 17 to 43 years with virus hepatitis and the other of five women aged 17 to 29 suffering from obstructive jaundice.

The diagnosis of virus hepatitis was based on the clinical course and laboratory findings and was supported by liver biopsy in eight patients. Six had used oral contraceptives for several months before admission to hospital. In the obstructive jaundice group the obstruction was caused in two patients by gall stones, in two by cholecystitis, and in one by fibrosis of the sphincter of Oddi. In four patients the diagnosis was verified at operation. In two the liver biopsy showed moderate cholestasis. One patient had taken an oral contraceptive for three months before her illness.

In the hepatitis group administration of oral contraceptives was started two weeks after the serum enzymes, except ornithine carbamyltransferase, had returned to normal. Six patients were given Volidan (ethinyloestradiol $0.05 \mathrm{mg}$ and megastrol acetate $4 \mathrm{mg}$ ) and four Lyndiol (mestranol $75 \mu \mathrm{g}$ and lynoestrenol $2.5 \mathrm{mg}$ ) one tablet daily. Four of the patients with obstructive jaundice were started on Volidan eight weeks after their operation and in the patient who was not operated on it was given two weeks after the serum enzymes returned to normal. The levels of serum aspartate aminotransferase (SGOT; normal under $20 \mathrm{IU} / 1$.), alanine aminotransferase (SGPT; normal under $18 \mathrm{IU} / 1$. ), ornithine carbamyltransferase (normal

First Medical Clinic, University of Helsinki, Helsinki 29, Finland A EISALO, M.D., Assistant Professor under 0.4 unit), alkaline phosphatase (normal under 2.9 BesseyLowry units), and total serum bilirubin were determined at two-weekly intervals.

\section{Results}

Hepatitis Group.-In the acute stage of the illness the highest serum levels of aspartate aminotransferase and alanine aminotransferase were 540 and $1,500 \mathrm{IU}$ respectively. The medians were 269 and 463 IU (Fig. 1). The highest level of ornithine carbamyltransferase was 2.63 units, of total serum bilirubin $14 \cdot 1 \mathrm{mg} / 100 \mathrm{ml}$, and of alkaline phosphatase $10 \cdot 2$ Bessey-Lowry units. Administration of contraceptives was started after the serum aspartate aminotransferase and alanine aminotransferase had become within normal limits and the alkaline phosphatase and total serum bilirubin had returned to normal, but in four patients the ornithine carbamyltransferase was still raised (0.53-0.68 unit). In some patients the serum aspartate aminotransferase and alanine aminotransferase rose above the normal upper limit during the first month of oral contraception, but they returned to normal afterwards. Likewise the serum ornithine carbamyltransferase gradually returned to normal in those cases in which it was raised when oral contraceptives were begun. The total serum bilirubin and alkaline phosphatase remained normal all through the follow-up.

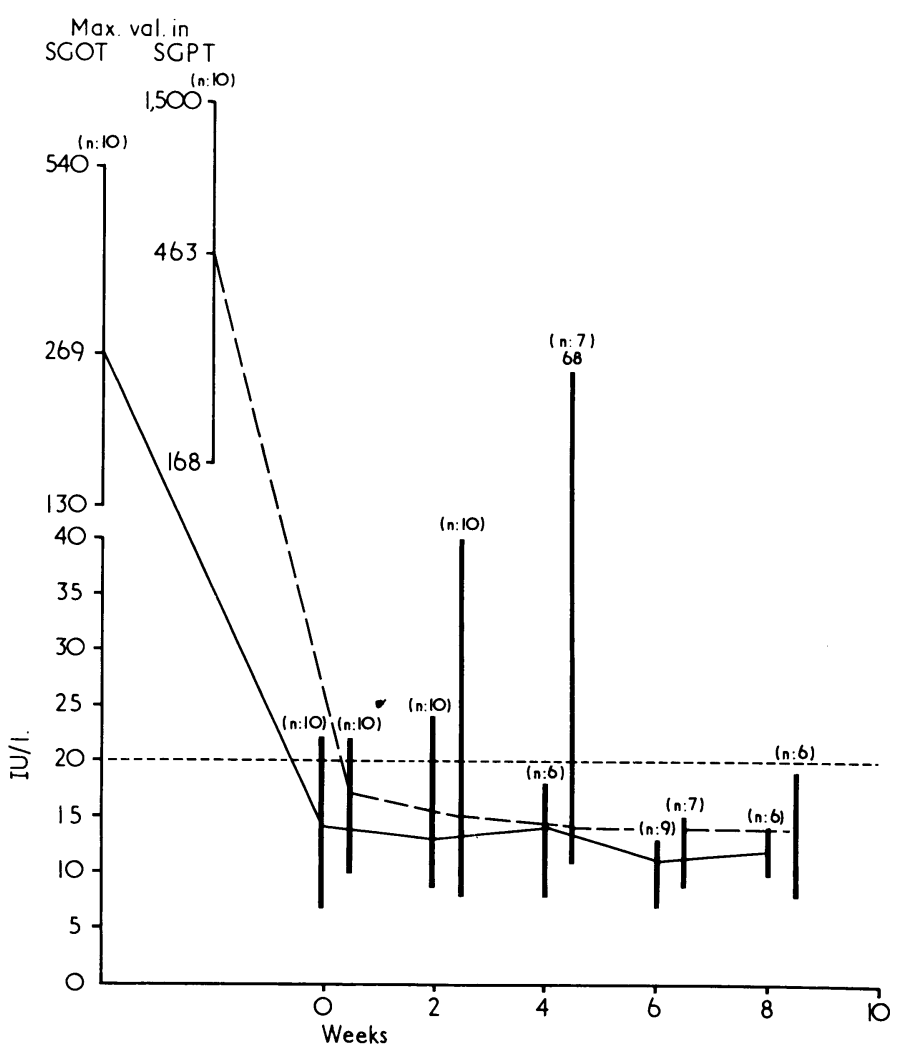

FIG. 1-SGOT and SGPT values in the hepatitis group. The vertical lines represent the range of the individual enzyme values. The first two show the range of the individual maximal values during the hyperacute stage of the illness. Administration of the pill was started at point 0 , at which time the enzyme values had been normal for two weeks. The median values are united with the continuous (SGOT) or interrupted (SGPT) lines. The horizontal interrupted line is the upper limit of the normal enzyme values. 
Obstructive faundice Group.-The maximal values in the acute stage varied from patient to patient as follows: total serum bilirubin $1 \cdot 5-5 \cdot 7 \mathrm{mg} / 100 \mathrm{ml}$, aspartate aminotransferase 25-182 IU, alanine aminotransferase 46-175 IU, ornithine carbamyltransferase $0 \cdot 66-2 \cdot 22$ units, and alkaline phosphatase 4.0-14.1 Bessy-Lowry units. When Volidan was being taken the serum enzymes stayed within normal limits except in one case (Fig. 2). In this woman, aged 21, the serum enzymes when Volidan was started were aspartate aminotransferase $22 \mathrm{IU}$, alanine aminotransferase $30 \mathrm{IU}$, ornithine carbamyltransferase 0.76 unit, and alkaline phosphatase 7.8 BesseyLowry units. The obstructive jaundice was caused in her case by acute cholecystitis. After 11 weeks on Volidan the serum aspartate aminotransferase was 25 IU and the alanine amino-

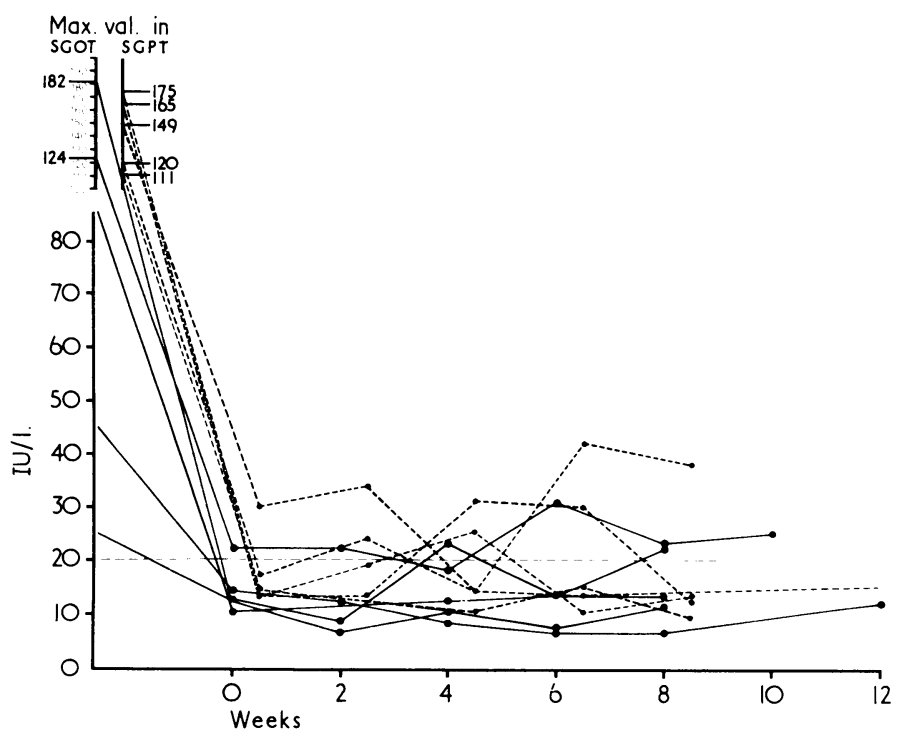

FIG. 2-SGOT (continuous lines) and SGPT (interrupted lines) values in five women with obstructive jaundice. The vertical lines represent the range of the individual maximal enzyme values in the hyperacute stage. Administration of the pill was started at point 0 -eight weeks after the operation in four patients, and in one when the enzyme values had been normal for two weeks. The horizontal interrupted line is the upper limit of the normal values.

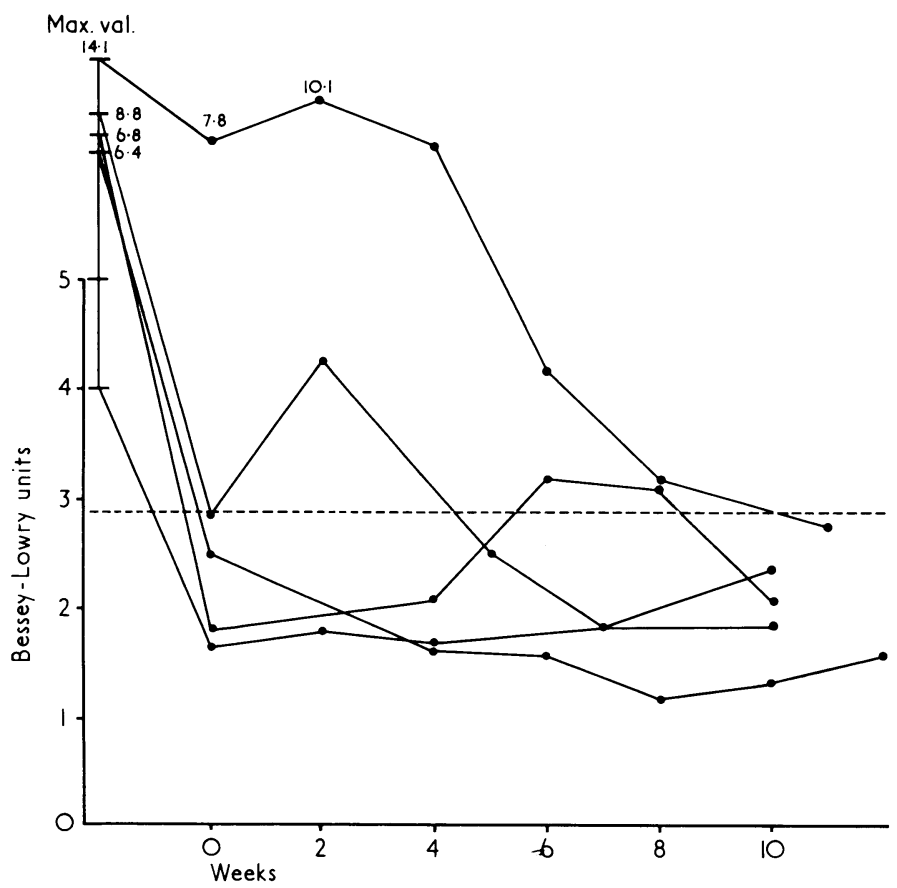

FIG. 3-Alkaline phosphatase in the obstructive jaundice group. The vertical line represents the range of the individual maximal values in the hyperacute stage. Administration of the pill was started at point $O$. The horizontal line is the upper limit of the normal value. transferase $38 \mathrm{IU}$. The total serum bilirubin remained throughout at $1 \mathrm{mg} / 100 \mathrm{ml}$. Despite cholestasis the raised alkaline phosphatase gradually fell to normal in 11 weeks (Fig. 3).

\section{Discussion}

Because many drugs are metabolized in the liver they must be prescribed with great caution in patients with acute liver damage. However, the ability to metabolize drugs is restored after reversible liver disease, and a return to normal of the liver function tests could be taken as a guide to when the administration of drugs could safely be resumed. We started oral contraceptives in our cases of virus hepatitis two weeks after the levels of serum aminotransferases returned to normal. These enzymes remained within normal limits while oral contraceptives were being taken. In some patients serum aminotransferases were slightly raised during the first month of administration, but they soon returned to normal. This is in agreement with earlier observations (Roman and Hecker, 1968; Hargreaves, 1970). On the other hand, the levels of serum ornithine carbamyltransferase either remained within normal limits all the time or gradually returned to normal without any transient fluctuations. The previous use of oral contraceptives did not seem to influence the clinical course of the hepatitis or the serum enzyme levels in the trial period.

In women who had recovered from obstructive jaundice the serum enzyme levels remained within normal limits while Volidan was being taken. In one patient an initial alka'ine phosphatase level of 7.8 Bessey-Lowry units gradually became normal. A lever biopsy specimen from this patient showed the type of cholestasis which has been reported to be typical in jaundice caused by oral contraceptives (Boake et al., 1965; Eisalo and Räsänen, 1965; Larsson-Cohn and Stenram, 1965). However, since the alkaline phosphatase and serum bilirubin were normal the cholestasis was not aggravated by oral contraceptives.

It seems reasonable to assume that some additional factor or factors must be present in the causation of jaundice or changes in the liver function tests by oral contraceptives. There is some evidence that the results of laboratory tests may be related to the dose of contraceptive, and alterations in the liver function tests seem more common in postmenopausal women than in women of childbearing age. Furthermore, it has been frequently reported that women in whom an oral contraceptive causes jaundice or abnormal liver function tests often have a history of jaundice in late pregancy (Adlercreutz and Ikonen, 1964; Boake et al., 1965; Haemmerli and Wyss, 1967; Schmid, 1969; Westerholm, 1970; Ylöstalo, 1970). Unfortunately one of the most essential questions-the significance of the molecular structure of the steroids in oral contraceptives and the possible individual differences in response to different steroids-remains unanswered. It will be clarified when the metabolic fate of the synthetic steroids is known.

We are indebted to Dr. Erkki Klemola, Head of Aurora Hospital, and Dr. Liisa Haapanen for allowing us to examine patients under their care.

\section{References}

Adlercreutz, H., and Ikonen, E. (1964). British Medical fournal, 2, 1133. Adlercreutz, H., and Ikonen, E. (1964). British Medical fournal, 2, 1133. Boake, W. C., Schade, S. G., Morrissey,
Annals of Internal Medicine, 63, 302.

Eisalo, A., and Räsänen, J. (1965). Annales Medicinae Internae Fenniae, 54, 47.

Haemmerli, U. P., and Wyss, H. J. (1967). Medicine, 46, 299.

Hargreaves, T. (1970). Fournal of Clinical Pathology, 23, Suppl. No. 3, p. 1 Larsson-Cohn, U., and Stenram, U. (1965). Fournal of the American Medical Association, 193, 422.

Roman, W., and Hecker, R. (1968). Medical fournal of Australia, 16, 682. Schmid, M. (1969). Deutsche medizinische Wochenschrift, 94, 1332

Westerholm, B. (1970). Skandia International Symposia: Alcoholic Cirrhosis and Other Toxic Hepatopathies, p. 251. Stockholm, Nordiska Bokhandelns.

Ylöstalo, P. (1970). Acta Obstetricia et Gynecologica Scandinavica, 49, Suppl. No. 4. 